\title{
HIV-1 Rev-binding protein accelerates cellular uptake of iron to drive Notch-induced T cell leukemogenesis in mice
}

\author{
Shariq S. Khwaja, ${ }^{1}$ Hudan Liu, ${ }^{2}$ Caili Tong, ${ }^{3}$ Fang Jin, ${ }^{3}$ \\ Warren S. Pear, ${ }^{2}$ Jan van Deursen, ${ }^{1,3}$ and Richard J. Bram ${ }^{3,4}$ \\ 1Department of Biochemistry and Molecular Biology, College of Medicine, Mayo Clinic, Rochester, Minnesota, USA. \\ 2Department of Pathology and Lab Medicine, University of Pennsylvania, Philadelphia, Pennsylvania, USA. \\ ${ }^{3}$ Department of Pediatric and Adolescent Medicine and ${ }^{4}$ Department of Immunology, College of Medicine, Mayo Clinic, Rochester, Minnesota, USA.
}

\begin{abstract}
Somatic activating mutations in Notch1 contribute to the pathogenesis of $T$ cell acute lymphoblastic lymphoma (T-ALL), but how activated Notch1 signaling exerts this oncogenic effect is not completely understood. Here we identify HIV-1 Rev-binding protein (Hrb), a component of the clathrin-mediated endocytosis machinery, as a critical mediator of Notch-induced T-ALL development in mice. $H r b$ was found to be a direct transcriptional target of Notch1, and Hrb loss reduced the incidence or delayed the onset of T-ALL in mouse models in which activated Notch1 signaling either contributes to or drives leukemogenesis. Consistent with this observation, Hrb supported survival and proliferation of hematopoietic and $\mathrm{T}$ cell precursor cells in vitro. We demonstrated that $\mathrm{Hrb}$ accelerated the uptake of transferrin, which was required for upregulation of the $T$ cell protooncogene $\mathbf{p} 21$. Indeed, iron-deficient mice developed Notch1-induced T-ALL substantially more slowly than control mice, further supporting a critical role for iron uptake during leukemogenesis. Taken together, these results reveal that $\mathrm{Hrb}$ is a critical Notch target gene that mediates lymphoblast transformation and disease progression via its ability to satisfy the enhanced demands of transformed lymphoblasts for iron. Further, our data suggest that Hrb may be targeted to improve current treatment or design novel therapies for human T-ALL patients.
\end{abstract}

\section{Introduction}

$\mathrm{T}$ cell acute lymphoblastic lymphoma (T-ALL) are serious hematologic malignancies of children and young adults. Current treatments that include intensive chemotherapy and cranial radiation are unsatisfactory, as they frequently cause severe long-term toxicities. Furthermore, significant numbers of patients die from recurrent disease, in spite of therapy. Better understanding of the molecular basis of lymphomagenesis will likely lead to improved therapy. The Notch receptor is implicated in the pathogenesis of T-ALL (1-3). Recent studies have demonstrated that Notch 1 is activated by somatic mutations in approximately $60 \%$ of cases of pediatric T-ALL (4). Notch 1 is a cell surface receptor that is activated by ligands from the DSL family. Ligand binding induces proteolytic cleavage of Notch 1 (S2), which is immediately followed by further cleavage by gamma-secretase (S3). This cleavage results in the release of the soluble Notch1 intracellular domain (ICN1), which translocates to the nucleus, where it activates transcription of target genes via its interaction with the DNA-binding protein CSL.

How Notch transforms T cell precursors remains a subject of intense study. Activated Notch has multiple pleiotropic effects in $\mathrm{T}$ cell precursors, which include dramatic acceleration of proliferation, increased thymocyte survival, and a block in differentiation (5). Preliminary studies on Notch inhibition by gamma-secretase inhibitors (GSIs) have demonstrated the importance of this signaling pathway in T-ALL. However, systemic toxicity limits the use of these drugs, and current efforts by many investigators focus on the

Conflict of interest: The authors have declared that no conflict of interest exists. Citation for this article: J Clin Invest. 2010;120(7):2537-2548. doi:10.1172/JCI41277. downstream molecular sequelae of Notch activation with the hope that they may provide useful therapeutic targets.

In previous studies, we found that mice bearing a conditional knockout allele of Creb-binding protein $(C B P)$ developed fatal $\mathrm{T}$ cell lymphomas with high penetrance. The transformed cells resembled immature thymocytes and had a $\mathrm{CD}^{+} \mathrm{CD}^{+}$double-positive (DP) phenotype (6). Microarray analyses revealed upregulation of multiple transcripts, including components of the Notch signaling pathway, c-myc, and the HIV-1 Rev-binding protein (Hrb). Hrb is an essential cofactor for HIV replication (7-9) and serves as an AP-2/EPS15 adapter required for vesicle fusion events that create the acrosome during spermatogenesis (10). Additionally, Hrb is implicated in clathrin-dependent endocytosis of VAMP7 (11) and the transferrin receptor (TfR) (12). However, it has not been implicated in oncogenesis. Here, we identify what we believe is a novel role for Hrb in T cell lymphomagenesis and find that it contributes significantly through its effects on transferrin uptake. In addition, we demonstrate what we believe is a novel function of $\mathrm{Hrb}$ in regulating protein levels of the $\mathrm{T}$ cell prosurvival factor p21 (WAF1/CIP1).

\section{Results}

Notch activation cooperates with CBP loss to accelerate Tcell lymphomagenesis. We previously observed that transcriptional targets of Notch 1 were upregulated in the majority of CBP-null $\mathrm{T}$ cell lymphomas (6), raising the possibility that activated Notch might have been a contributing factor to their development. If Notch indeed cooperates with CBP loss, then activation of Notch by use of a transgene might accelerate $\mathrm{T}$ cell lymphomagenesis in CBP-null mice. Thus, we generated mice that had both a conditional deletion of $C B P$ and 


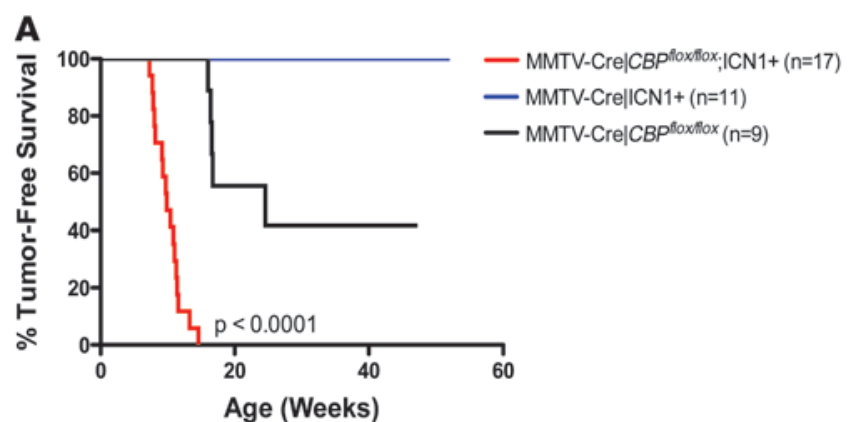

B Control

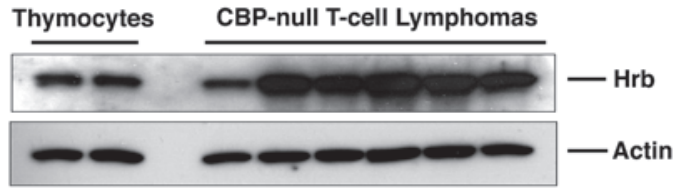

that expressed the intracellular activated form of Notch1 (ICN1) (13). ICN1 transgenic mice developed T cell lymphomas around 98 weeks (data not shown). Mice with the ICN1 transgene combined with CBP loss developed $\mathrm{T}$ cell lymphomas much faster than littermate control animals that were singly CBP-null or ICN1-transgenic ( $P<0.0001$ by Mantel-Cox log-rank analysis) (Figure 1A), consistent with the notion that activated Notch could synergize with loss of CBP to generate $\mathrm{T}$ cell lymphoma.

$H r b$ is a direct transcriptional target of Notch1. Hrb mRNA levels were significantly elevated in T cell lymphomas from CBP-null mice (6). To verify whether this was also reflected at the protein level, we prepared lysates from 6 independent spontaneous $T$ cell lymphomas from CBP-null mice and analyzed Hrb protein by Western blotting. Five out of 6 tumors expressed dramatically higher levels of Hrb protein compared with nontransformed thymocytes (Figure 1B).

In an independent study, Weng et al. investigated changes in gene expression in T-ALL cells following Notch1 inhibition. Among their results was the finding that Hrb transcript levels were reduced following Notch inactivation (14). In addition, microarray analyses of several murine T-ALL cell lines have consistently shown Hrb to be regulated by Notch1 (W.S. Pear, unpublished observations). To address whether Hrb is directly regulated by Notch 1 signaling, we utilized the Notch-dependent murine T-ALL cell line T6E12 (15). Transfection of cells with a dominant negative MAML1 construct (DNMAML1) or treatment with GSI decreased Hrb mRNA and protein levels (Figure 2B), accompanied by progressive cell growth arrest/death. Expression of a constitutively active, GSI-insensitive form of Notch1, ICN1, restored Hrb mRNA levels even in the presence of GSI. Treatment of T-ALL cells with GSI resulted in the accumulation of a transmembrane-tethered form of Notch that can be rapidly cleaved to the intracellular activated form (ICN1) upon GSI removal. GSI washout resulted in the derepression of $\mathrm{Hrb} \mathrm{mRNA}$, even in the presence of the protein synthesis inhibitor cycloheximide, suggesting that Hrb could be a direct transcriptional target of Notch1 (Figure 2B). Analysis of the Hrb gene revealed CSL-binding sites approximately $32 \mathrm{~kb}$ upstream of the Hrb promoter (site A: $-32 \mathrm{~kb}$, TGTGGGAA) and following exon 1 in the first intron (site B: +180 bp, CGTGGGTA), which could potentially allow Notch 1 to initiate transcription of the gene. Using ChIP, we detected CSL binding to both of these sites (Figure 2C), albeit much stronger at site A. GSI treatment

\section{Figure 1}

Notch activation cooperates with $C B P$ loss to accelerate lymphomagenesis. (A) Kaplan-Meier survival curve of mice with either (a) conditional deletion of $C B P^{f l o x}$ fllox via an MMTV-Cre mediated excision $(n=9)$, (b) transgenic expression of ICN1 via MMTV-Cre mediated excision of a floxed STOP sequence sandwiched between the chicken $\beta$-actin promoter and ICN1 coding sequence $(n=11)$, or (c) transgenic for ICN1 expression and CBP-null $(n=17) . P<0.0001$ using log-rank (Mantel-Cox) test. ICN1 transgenic mice developed T cell lymphomas around 98 weeks. (B) Western blot of lysates prepared from control thymocytes and 6 CBP-null T cell lymphomas, blotting for Hrb (clone 386-562) and actin (loading control).

depleted ICN1 from these sites. These data strongly suggest that Notch 1 acts directly to induce Hrb transcription. We also observed that Hrb transcript levels were highest during the double-negative (DN) stage of thymocyte development when Notch signaling is believed to be most active. These levels subsequently dropped during the DP stage, when Notch is believed to be turned off (Supplemental Figure 6; supplemental material available online with this article; doi:10.1172/JCI41277DS1).

Next, we asked whether Notch1 signaling would significantly alter the protein levels of Hrb in a primary $\mathrm{T}$ cell system. Thymocytes were prepared from WT mice and sorted to purify the earliest thymic-precursor $\mathrm{CD}^{-}{ }^{-} \mathrm{CD} 8^{-} \mathrm{DN}$ cells. These were seeded onto irradiated beds of OP9DL1 cells to provide low-level Notch stimulation that would allow their survival and proliferation (16). Expression of activated (oncogenic) Notch1 was enforced by transduction with a retrovirus (Mig-ICN1). In these conditions, Hrb protein levels were dramatically increased (Figure 2D). Together, these experiments suggested that elevated Notch1 signaling in $\mathrm{T}$ cell lymphomas was responsible for the high-level expression of $\mathrm{Hrb}$.

Hrb is crucial for CBP-null lymphomagenesis. To explore whether Hrb might participate in oncogenesis, we generated cohorts of $\mathrm{Hrb}^{+/+}$ and $\mathrm{Hrb}^{-/-}$mice in addition to conditional deletion of CBP in the thymus. These mice were followed for up to 90 weeks. We observed a 70\% reduction in the incidence of T cell lymphomas in the $\mathrm{Hrb}^{-/-}$ mice in comparison with $\mathrm{Hrb}^{+/+}$littermate controls (15\% vs. $50 \%$, $P=0.0396$ by Mantel-Cox log rank analysis) (Figure 3A), indicating that Hrb plays a critically important role in efficient tumor formation due to loss of CBP in thymocytes.

Hrb expression was highly induced above basal levels in all lymphomas that had Notch1 upregulation (Figure 3B). However, Hrb could also be induced by alternative pathways, since high-level Hrb was detected in some tumors lacking Notch1 (Figure 3B). Additionally, the upregulation of Hrb in CBP-null tumors correlated with Notch activation as demonstrated with an antibody that detects the gamma-secretase cleaved form of Notch1 (Figure 3C).

Hrb is not required for physiologic Notch signaling. Although the initial site of transformation in T-ALL is not known, we postulated that either a committed lymphoid precursor in the BM or an earlystage thymocyte would be a likely candidate target cell, because of the phenotype of most lymphoma cells that arise in CBP-null or Notch-transgenic mice (CD4-positive, CD8-positive). If loss of the Hrb gene would cause a defect in thymocyte development, this would be a relatively trivial mechanism underlying its protective effect in preventing T-ALL in the absence of CBP (Figure 3A). To test this possibility, we examined thymi from $\mathrm{Hrb}^{+/+}, \mathrm{Hrb}^{+/}$, and $\mathrm{Hrb}^{-/-}$mice. These studies revealed an equal number of total thy- 
A

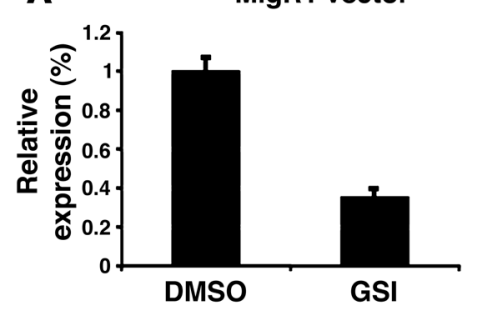

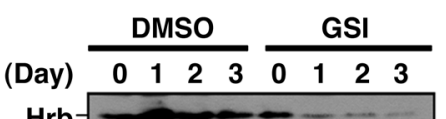

Actin

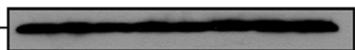

MigR1-ICN1
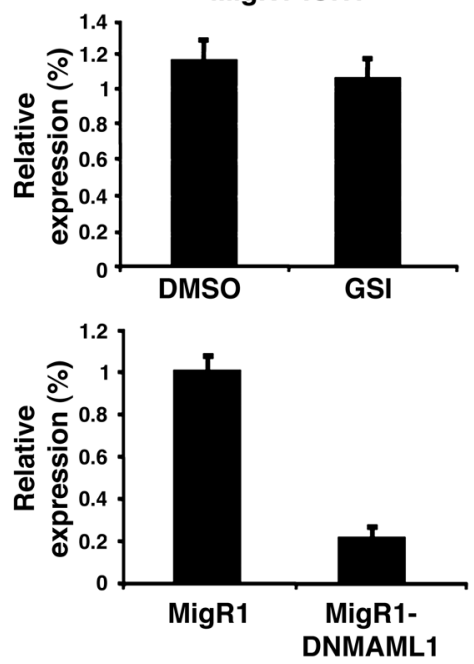

B

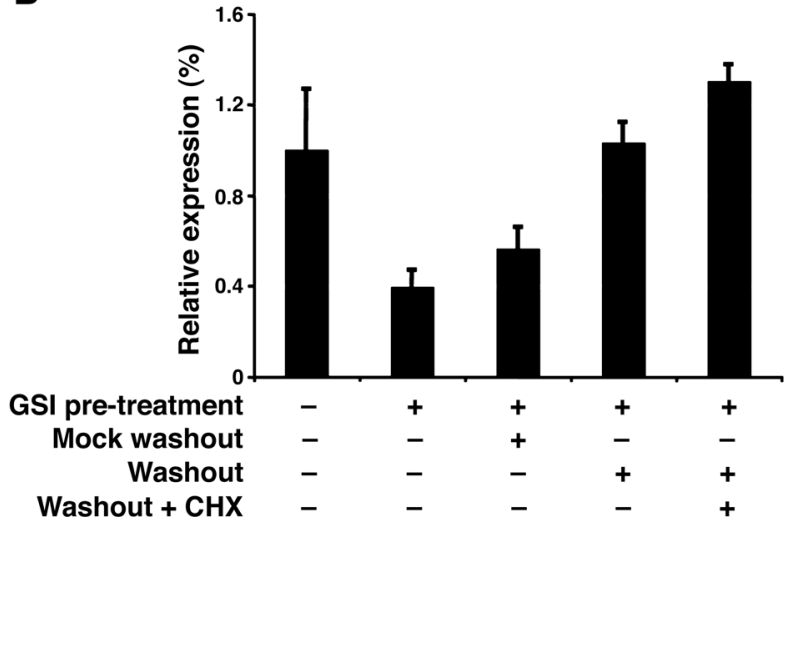

C

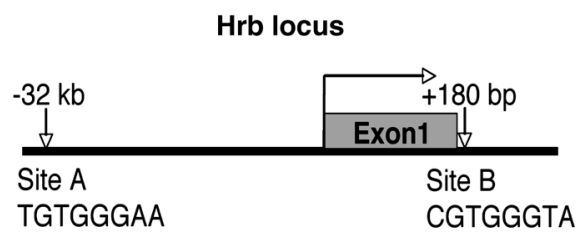

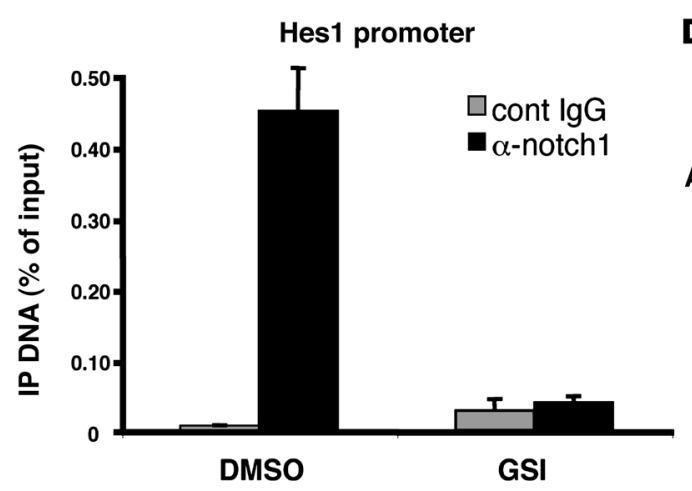

Hrb site B (180 bp)

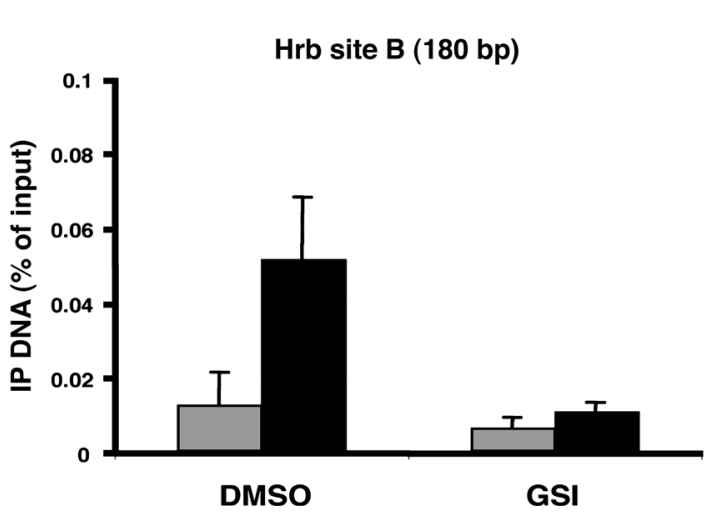

$\mathrm{Hrb}^{+/+} \quad \mathrm{Hrb}^{-/}$ MigR1 ICN1MigR1 ICN1
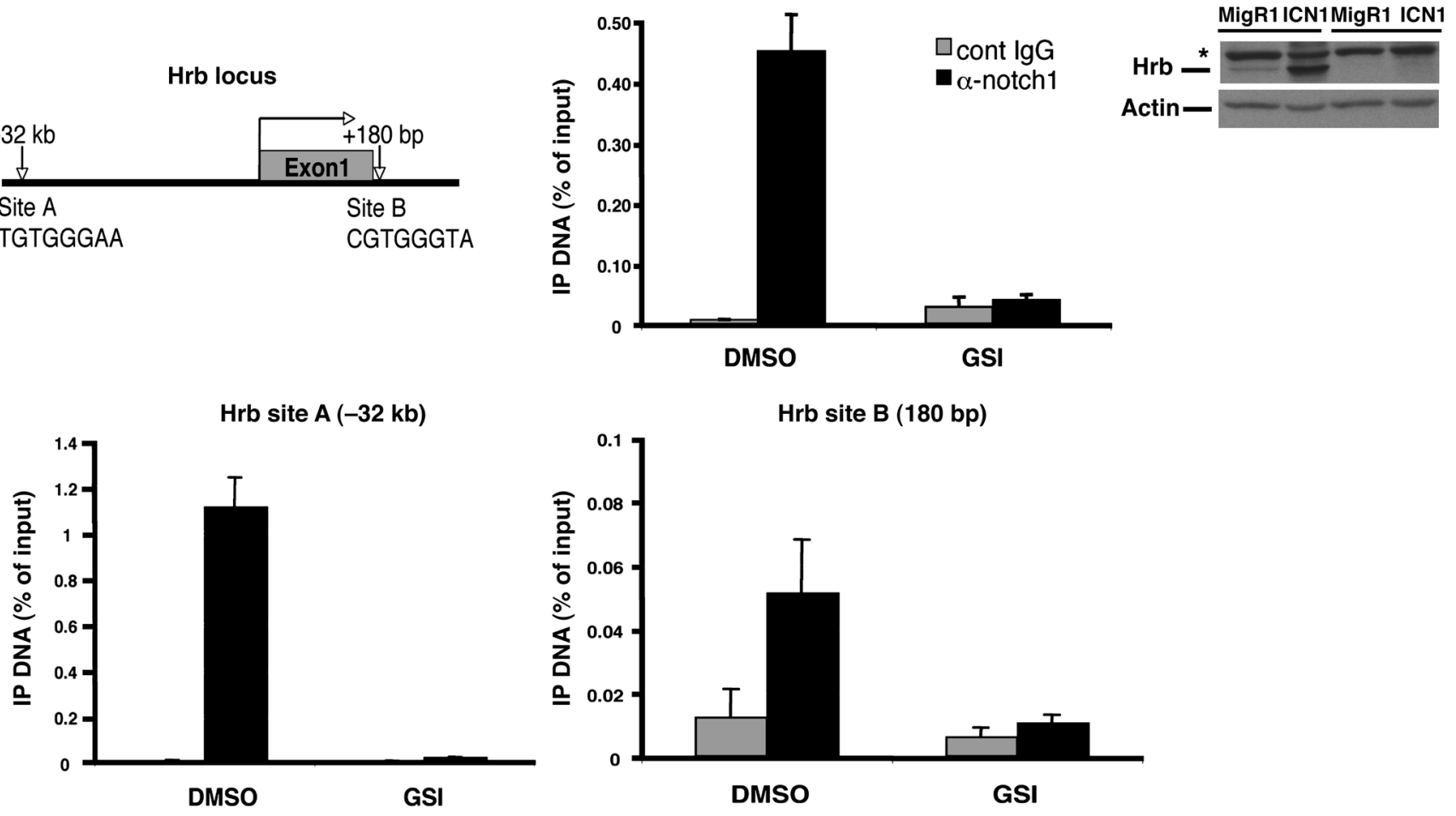

Figure 2

$\mathrm{Hrb}$ is a direct Notch1-regulated transcriptional target. (A) A murine Notch-dependent cell line, T6E12, was utilized for Hrb mRNA and protein analysis. T6E12 cells were transduced with MigR1 (empty vector), MigR1-ICN1, or MigR1-DNMAML1 for 48 hours followed by 24 hours DMSO or GSI $(1 \mu \mathrm{M})$ treatment as labeled. Hrb mRNA and protein levels were determined by quantitative RT-PCR and Western blot analysis, respectively. Results were obtained from 3 independent experiments. (B) T6E12 cells were treated with GSI ( $1 \mu \mathrm{M})$ for 48 hours to permit accumulation of the gamma-secretase substrate (transmembrane-Notch1 [NTM]). Cells were then washed and replenished with medium containing GSI (mock washout) or medium lacking GSI (washout) in the absence or presence of $20 \mu \mathrm{M}$ cycloheximide (CHX). Hrb mRNA levels were evaluated by quantitative RT-PCR after 4 hours of additional incubation. Similar results were obtained in 3 independent experiments. (C) ChIP was performed on cross-linked fragmented DNAs prepared from T6E12 cells treated with DMSO or $1 \mu \mathrm{M}$ GSI for 24 hours. Eluted DNAs were then analyzed by quantitative RT-PCR using primers flanking putative CSL-binding sites ( $A$ and B). Amplification of hes 1 CSL-binding site served as a positive control to validate ChIP efficiency. The amount of DNA amplified from immunoprecipitated DNAs was normalized to that amplified from input DNA. (D) Western blot of lysates prepared from empty vector- (MigR1) and ICN1-transduced $\mathrm{Hrb}^{+/+}$and $\mathrm{Hrb}^{-/-}$T cell precursors blotted for Hrb (clone $\mathrm{H}-300)$ and actin (loading control). Asterisk indicates nonspecific band. Data are shown as mean \pm SD. 
A

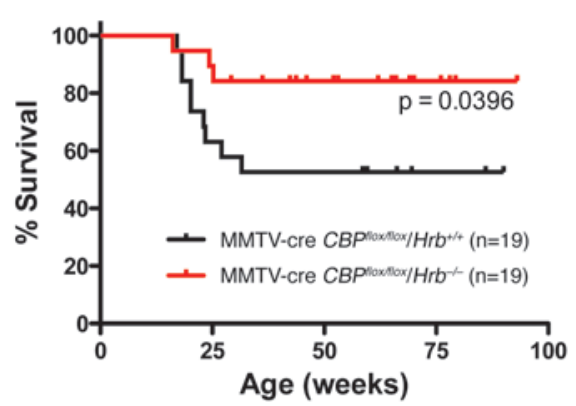

B

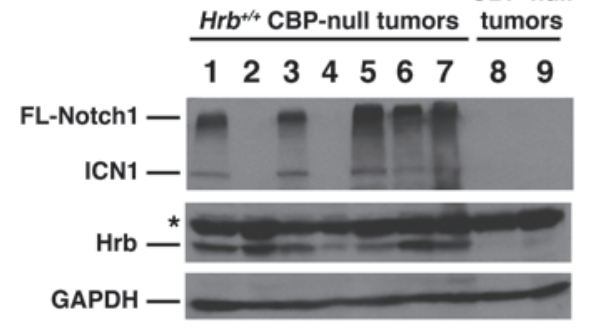

C

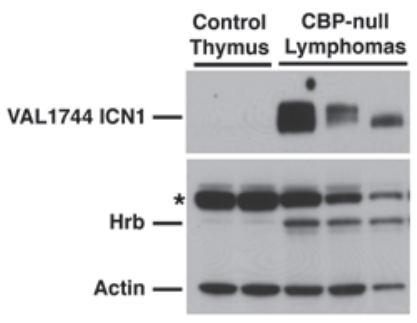

\section{Figure 3}

$\mathrm{Hrb}$ is required for efficient CBP-null lymphomagenesis. (A) Kaplan-Meier survival curve of $\mathrm{Hrb}^{+/+}$and $H r b^{-/-}$cohorts monitored over a period of 90 weeks. Hrb ${ }^{+/-}$mice on the background of MMTV-Cre/CBPflox/flox were intercrossed to generate $\mathrm{Hrb}^{+/+}$and $\mathrm{Hrb}^{-/-}$mice with conditional Ioss of CBP. Mice were sacrificed once moribund and confirmed via dissection for the occurrence of T cell lymphoma ( $n=19$ for each cohort; $P=0.0396$, log-rank Mantel-Cox test). (B) Western blot of lysates prepared from $\mathrm{Hrb}^{+/+} \mathrm{CBP}$-null tumors $(n=7)$ and $\mathrm{Hrb}^{-/-} \mathrm{CBP}$-null tumors $(n=2)$. Membrane was blotted for Notch1 protein (clone mN1a), Hrb (clone H-300), and GAPDH (loading control). (C) Western blot of lysates prepared from CBP-null tumors $(n=3)$ and control thymocytes $(n=2)$. Membrane was blotted for activated Notch (VAL1744 Ab), Hrb (clone $\mathrm{H}-300$ ), and actin (loading control). Asterisks indicate nonspecific bands.

mocytes (Supplemental Figure 1A), and also completely normal CD4-CD8- DN (Supplemental Figure 1B), $\mathrm{CD}^{+}{ }^{+} \mathrm{CD}^{+}{ }^{+} \mathrm{DP}, \mathrm{CD}^{+}{ }^{+}$ single-positive (SP), and CD8 ${ }^{+}$SP subsets (Supplemental Figure $1 C)$. In addition, analysis of the TCR- $\beta$ repertoire by an RT-PCR method (17) revealed results virtually identical to those from $\mathrm{Hrb}^{+/+}$ and $\mathrm{Hrb}^{-/}$splenocytes. We conclude that $\mathrm{Hrb}$ is not required for normal thymocyte development at various stages. Finally, Hrb was not required for expansion of stimulated peripheral $\mathrm{T}$ cells (Supplemental Figure 4).

Hrb is required for efficient ICN1-induced leukemogenesis. Since Hrb is a direct transcriptional target of Notch and Notch activation cooperates with CBP loss to accelerate lymphomagenesis, we asked whether Hrb participates in Notch-induced tumorigenesis using a well-characterized BM transduction and transplantation model (18). $\mathrm{Hrb}^{-/-}$and littermate control mice were treated with 5-FU to enrich for hematopoietic stem cells, which were transduced with control virus (MigR1) or ICN1-expressing retrovirus. Equal transduction efficiencies were verified by flow cytometric detection of GFP (Figure 4A) and semiquantitative RT-PCR of ICN1 mRNA (data not shown). Transduced BM cells were transferred to lethally irradiated wild-type recipients, which were then observed for onset of T-ALL over the next several months. These experiments revealed a clear requirement for $\mathrm{Hrb}$ in efficient ICN1-induced leukemogenesis (Figure 4B). The median survival of mice receiving $\mathrm{Hrb}^{+/+}$ ICN1-transduced BM was 27.5 days after BM transplant (BMT). Median survival of mice receiving $\mathrm{Hrb}^{-1-} \mathrm{ICN} 1$-transduced $\mathrm{BM}$ was approximately 2 -fold longer at 54.0 days after transplant $(P<0.0001$ by Mantel-Cox log rank analysis). Mice that received control retrovirus-transduced BM cells of either WT or $\mathrm{Hrb}^{-/-}$genotype did not develop leukemia and had normal engraftment and survival. Analysis of the peripheral blood from transplant recipients 15 days after BMT revealed an accumulation of $\mathrm{GFP}^{+} \mathrm{DP}$ cells in both $\mathrm{Hrb}^{+/+} \mathrm{ICN} 1$ and $\mathrm{Hrb}^{-/-}$ICN1 recipients (Figure 4C). Additionally, splenocyte (Figure 4D) and BM (Figure 4E) analyses performed 26 days after BMT also showed an equal accumulation of $\mathrm{GFP}^{+} \mathrm{DP}$ cells in both $\mathrm{Hrb}^{+/+}$and $\mathrm{Hrb}^{-/-}$ICN1-transduced BM recipients. Thus, we do not suspect that the significant delay in development of T-ALL in $\mathrm{Hrb}^{-/-}$cells was a result of failed engraftment. BM iso- lated from $\mathrm{Hrb}^{-/-}$ICN1 transplants did show reduced numbers of $\mathrm{GFP}^{+}$cells and an increased percentage of $\mathrm{GFP}^{+} \mathrm{CD}^{+} \mathrm{SP}$ cells (Supplemental Figure 5).

Hrb is required for growth and survival of ICN1-transduced hematopoietic and T cell precursors. To investigate the mechanism of $\mathrm{Hrb}$ in oncogenic Notch signaling, we cultured hematopoietic precursors from $\mathrm{Hrb}^{+/+}$and $\mathrm{Hrb}^{-/-}$BM on OP9 stromal cells, transduced with ICN1, and then monitored cells for growth over a period of 7 days. ICN1-transduced BM cells that were $\mathrm{Hrb}^{-/-}$had reduced growth and increased death as measured by annexin $\mathrm{V} /$ propidium iodide (PI) staining, compared with $\mathrm{Hrb}^{+/+}$cells (Figure 5, A and B). Retroviral mediated reexpression of $\mathrm{Hrb}$ rescued both defects. Next, we isolated CD4-CD8 ${ }^{-}$DN thymocytes from $\mathrm{Hrb}^{+/+}$and $\mathrm{Hrb}^{-/-}$mice and plated these T cell precursors onto OP9DL1 stromal cells. Upon transduction with ICN1, loss of $\mathrm{Hrb}$ was associated with a marked reduction in cell numbers in all 3 thymocyte subsets (DN, CD8 immature SP [ISP], and DP) that developed after 5 days in these cocultures, in comparison with wild-type cells (Figure 5C). We verified that $\mathrm{Hrb}$ protein levels were significantly upregulated in both hematopoietic precursors and $\mathrm{T}$ cell precursors (Figure 5D) transduced with ICN1.

Hrb loss increases surface $C D 71$ and is required for efficient transferrin uptake. Hrb is important for the internalization of cell surface VAMP7 and delivery to the lysosomal membrane (11) and efficient clathrin-dependent endocytosis (12). The TfR (CD71) is a well-known substrate for clathrin-dependent endocytosis (19-22), and its endocytosis and trafficking are critically important for its essential role in cellular uptake of iron in the form of holo-transferrin. Intriguingly, transferrin and TfR have both been implicated in thymocyte development (23-25) and TfR has been found to be elevated on immature cycling thymocytes (26) and leukemias $(27,28)$. Therefore, we asked whether Hrb might participate in regulation of CD71 in the context of oncogenic Notch signaling. DN thymocytes cultured on OP9DL1 cells were transduced with control or ICN1-expressing retrovirus and cultured for 5 days. CD71 at the cell surface detected by flow cytometry after antibody staining revealed several important findings. First, DN cells had higher levels of CD71 than subsequent developmental 
A

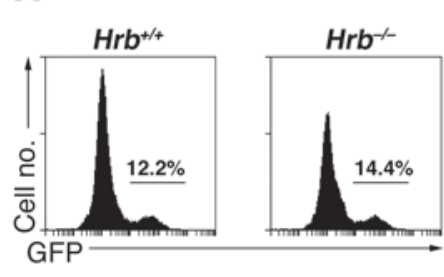

C

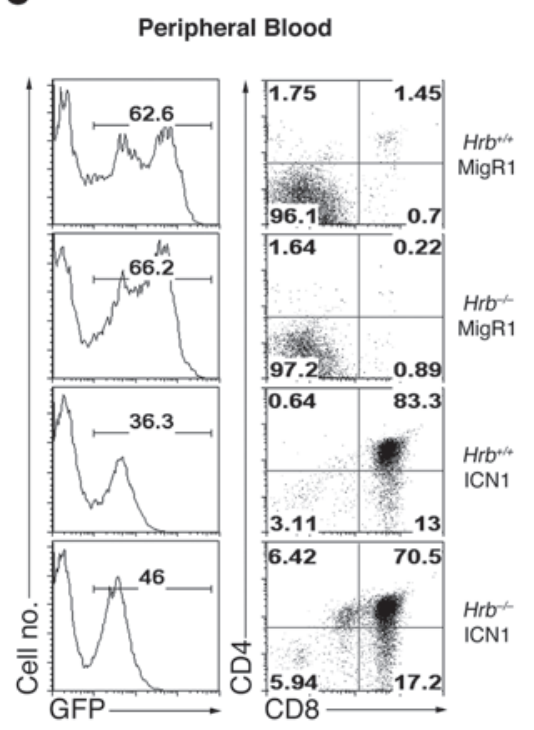

B

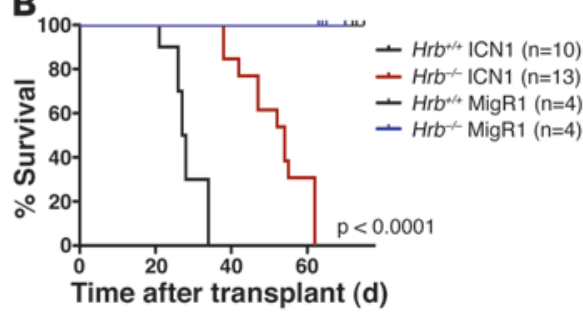

D

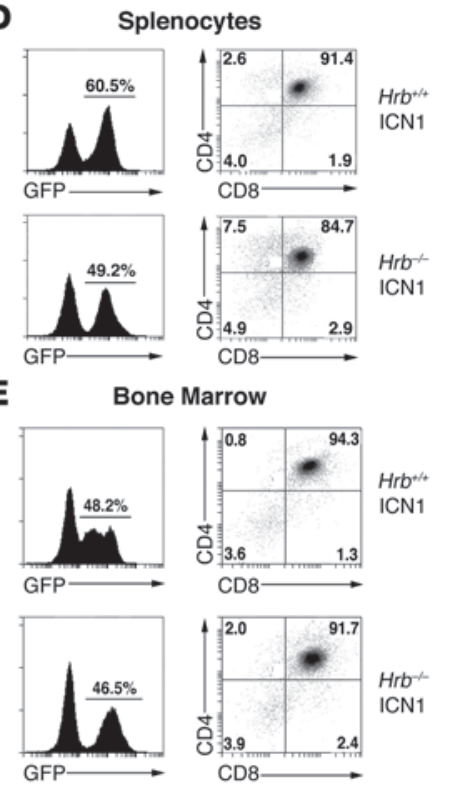

\section{Figure 4}

Hrb is required for efficient ICN1-induced leukemogenesis. (A) Analysis of GFP expression in $\mathrm{Hrb}^{+/+}$and $\mathrm{Hrb}^{-/-} \mathrm{BM}$ after transduction with ICN1-expressing retrovirus and before transplantation into lethally irradiated recipients. Numbers in each GFP histogram refer to the GFP-positive percentage. (B) Kaplan-Meier survival curve of mice receiving $\mathrm{Hrb}^{+/+} \mathrm{ICN} 1-$ transduced BM $(n=10)$, $\mathrm{Hrb}^{-/-}$ICN1-transduced BM $(n=13), \mathrm{Hrb}^{+/+}$MigR1transduced BM $(n=4)$, and $\mathrm{Hrb}^{-/-}$MigR1-transduced BM $(n=4)$. Statistical significance was established using the Mantel-Cox log rank analysis and showed a significant increase in survival in mice receiving $\mathrm{Hrb}^{-1-} \mathrm{ICN} 1-$ transduced BM $(P<0.0001)$. Median time of survival after BMT for mice receiving $\mathrm{Hrb}^{+/+}$ICN1transduced BM was 27.5 days. Median time of survival after BMT for mice receiving $\mathrm{Hrb}^{-/-}$ICN1-transduced BM was 54 days. Mice receiving MigR1-transduced BM did not succumb to disease. (C) GFP analysis and $\mathrm{CD}^{+}{ }^{+} \mathrm{CD} 8^{+}$surface staining of peripheral blood cells isolated 15 days after BMT from mice receiving $\mathrm{Hrb}^{+/+}$ and $\mathrm{Hrb}^{-/-}$MigR1- and ICN1-transduced BM cells. (D-E) GFP analysis and CD4+CD8 ${ }^{+}$surface staining of splenocytes (D) and BM cells (E) isolated from mice receiving $\mathrm{Hrb}^{+/+}$and $\mathrm{Hrb}^{-/-}$ICN1-transduced BM cells. Numbers in GFP histograms refer to the percentage of GFP-positive cells. Numbers in each dot plot refer to the percentages in each quadrant. stages, consistent with their high rates of proliferation (29). Furthermore, ICN1 expression induced higher levels of CD71 at each developmental stage (Figure 6A). The most striking finding was that $\mathrm{Hrb}^{-/-}$cells, either with or without ICN1, had higher surface CD71 than $\mathrm{Hrb}^{+/+}$cells (Figure 6A). $\mathrm{Hrb}^{-/-} \mathrm{BM}$ hematopoietic precursors transduced with ICN1 also expressed significantly higher surface CD71 compared with WT controls (Figure 6B). The high levels of surface CD71 in knockout cells was reduced to WT levels with reexpression of $\mathrm{Hrb}$.

To test the function of CD71, cells were incubated with fluorescently labeled transferrin for various periods of time, washed, and then analyzed by flow cytometry to detect uptake. As expected from the increased surface CD71, expression of ICN1 caused a more rapid and greater final uptake of transferrin both in WT and in $\mathrm{Hrb}^{-/-}$cells compared with MigR1-transduced cells (Figure 6, $\mathrm{C}$ and D). Loss of Hrb in ICN1-expressing DP cells caused a relative reduction in the uptake of transferrin, in spite of their slightly higher CD71 levels. In the case of ICN1-transduced DN and CD8 ISP cells, transferrin uptake was equal between $\mathrm{Hrb}^{-/-}$and $\mathrm{Hrb}{ }^{+/+}$ cells (Supplemental Figure 2, A and B), even though there were significantly higher CD71 levels on the $\mathrm{Hrb}^{-/-}$cells. Together, these studies suggest that transferrin uptake is less efficient in cells lacking $\mathrm{Hrb}$ if they also express ICN1.

Efficient transferrin uptake and subsequent utilization of iron are essential for rapidly growing cells in order to support cell division. We wondered, therefore, whether the defect in proliferation and survival seen in ICN1-expressing $\mathrm{Hrb}^{-/-}$cells could, in part, be explained by insufficient availability of transferrin. Although the mutant cells had inefficient uptake, we found that increasing the extracellular transferrin did lead to increased uptake (Figure 6D). To bypass the $\mathrm{Hrb}^{-/-}$defect, we cultured hematopoietic precursors transduced with ICN1 in the presence of excess transferrin. Under these conditions, mutant cells recovered their ability to proliferate in vitro, while the addition of excess transferrin had little effect on WT cells (Figure 6E). This was accompanied by a significant reduction in cell surface CD71 as well (Figure 6F). To further confirm that iron supplementation can rescue the defect in $\mathrm{Hrb}^{-/-} \mathrm{ICN1}$ transduced cells, we incubated DN T cell precursors with ferric ammonium citrate (FAC), a compound that stimulates a transferrin-independent uptake of iron (30). Similar to the results of holo-transferrin addition, FAC addition rescued the $\mathrm{Hrb}^{-/-}$defect in proliferation, but had little effect on WT cells (Supplemental Figure 3 ). These results strongly suggested that inefficient iron utilization was a major factor limiting the proliferation and survival of ICN1-expressing $\mathrm{Hrb}^{-/-}$cells.

Consistent with the increased surface expression of CD71 following ICN1 transduction, total cellular levels of CD71 were also induced compared with MigR1 controls (Figure 6G). Poor transferrin uptake and/or trafficking in the absence of Hrb might explain why CD71 levels were higher on mutant cells, since translation of the TfR mRNA is increased when intracellular levels of iron are low. Western blotting indicated that total cellular levels of CD71 were indeed elevated in $\mathrm{Hrb}^{-/-}$MigR1- and ICN1-transduced cells (Figure 6G). As predicted, total cellular CD71 in $\mathrm{Hrb}^{-/-}$ICN1-transduced cells decreased in the presence of excess holo-transferrin. 

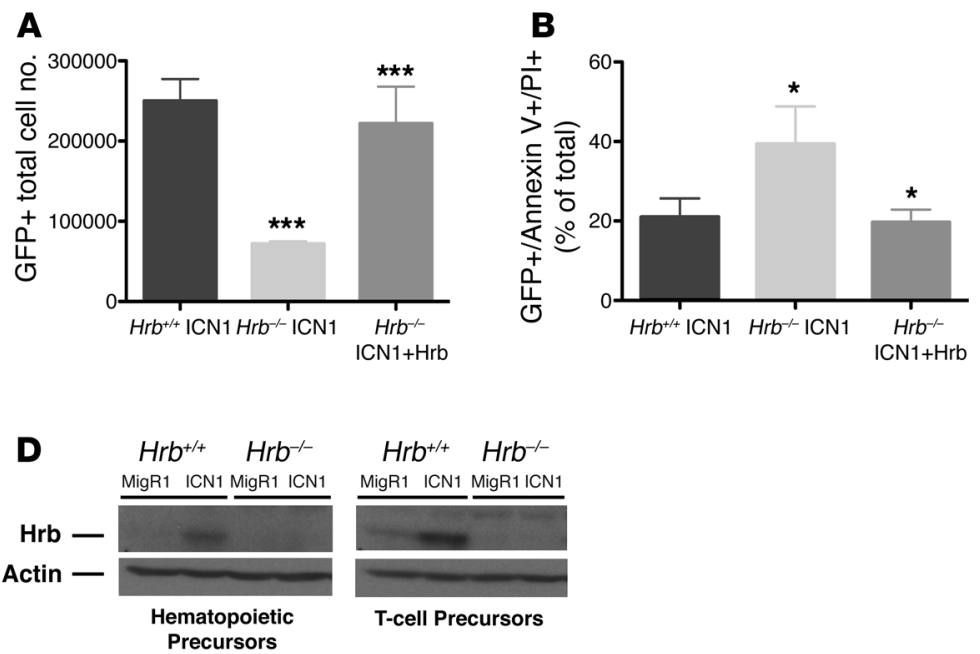

$\mathrm{Hrb}^{+/+} \mathrm{Hrb}-/$ MigR1 ICN1 MigR1 ICN1

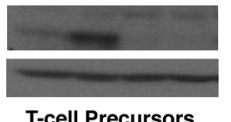

T-cell Precursors

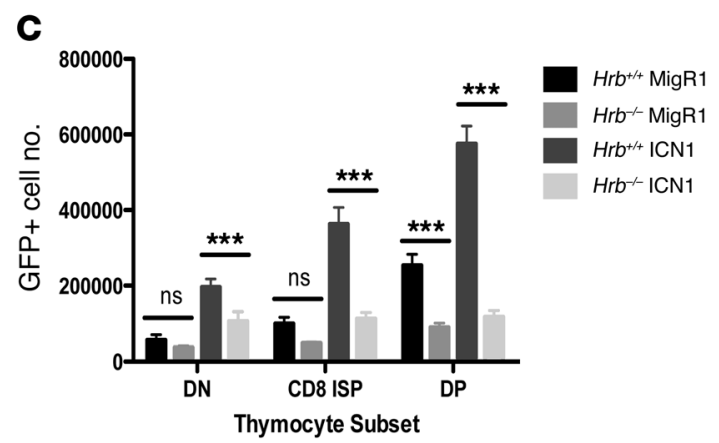

Figure 5

$\mathrm{Hrb}$ is required for growth and survival of ICN1-transduced hematopoietic and T cell precursors. (A) GFP-positive total cell number of $\mathrm{Hrb}^{+/+}$ ICN1-, $\mathrm{Hrb}^{-1-} \mathrm{ICN1} 1-$, and $\mathrm{Hrb}^{-/-}$ICN1+Hrb-transduced hematopoietic precursor cells cocultured on OP9 stromal beds and harvested 7 days after transduction. (B) GFP-positive and annexin V and/or PI-positive percentages in Hrb ${ }^{+/+}$ICN1-, Hrb ${ }^{-/-}$ICN1-, and Hrb ${ }^{-/-}$ICN1+Hrb-transduced hematopoietic precursor cells 7 days after transduction. (C) GFP-positive cell number of $\mathrm{Hrb}^{+/+}$and $\mathrm{Hrb}^{-/-}$MigR1-and ICN1-transduced thymocytes grown on OP9DL1 stromal beds, harvested 5 days after transduction, and stained with antibodies to CD4 and CD8 to determine numbers in the CD4-CD8- DN, CD4-CD8+ ISP (CD8 ISP), or CD4+CD8+ DP subsets. (D) Western blot of lysates prepared from $\mathrm{Hrb}^{+/+}$and $\mathrm{Hrb}^{-/-} \mathrm{MigR} 1-$ and ICN1-transduced hematopoietic precursors (left) and $\mathrm{Hrb}^{+/+}$and $\mathrm{Hrb}^{-/-}$MigR1- and ICN1-transduced T cell precursors (right) blotted for Hrb (clone $\mathrm{H}-300$ ) and actin (loading control). Data are shown as mean $\pm \mathrm{SD} .{ }^{*} P<0.05 ;{ }^{* *} P<0.001$.

Hrb regulates $p 21$ protein levels via transferrin uptake. Iron is important in several cellular processes $(31,32)$ and particularly in cell cycle progression and survival. One such component that is dependent upon iron is the p21 (CIP1/WAF1) protein, a cdk inhibitor that has been shown in various systems to halt cell cycle progression (33-37). However, there is also evidence to suggest that p21 can promote cell cycle progression since it is required for the assembly of cyclin DCDk complexes (38) and that it serves a prosurvival function in breast cancer $(38,39)$ and thymic lymphoma (40). Moreover, there is evidence that p21 can inhibit apoptosis directly by preventing activation of caspase 3 (41) or apoptosis signal-regulating kinase 1 (ASK1) (42).

Although transcript levels of p21 were unaltered, we found that $\mathrm{p} 21$ protein levels were dramatically increased after ICN1 transduction of WT thymocytes. This induction was almost completely lacking in $\mathrm{Hrb}^{-/-}$cells (Figure 7, A and C). Importantly, the transcript levels of $\mathrm{p} 21$ were equal between $\mathrm{Hrb}^{+/+}$and $\mathrm{Hrb}^{-/-}$ ICN1-transduced thymocytes (Figure 7B). p21 has been shown to be regulated at the posttranscriptional level by intracellular iron status (43). Accordingly, we found that addition of increasing concentrations of excess transferrin to $\mathrm{Hrb}^{-/-}$cell cultures resulted in the rescue of $\mathrm{p} 21$ protein levels to those seen in $\mathrm{Hrb}^{+/+}$ ICN1-transduced thymocytes (Figure 7C). To determine whether overexpression of $\mathrm{p} 21$ by itself could increase cell numbers in $\mathrm{Hrb}^{+/+}$ICN1-transduced hematopoietic precursor cells, we cotransduced these cells with $\mathrm{p} 21$-expressing retroviral vectors and monitored cell numbers over a period of 7 days. We found a more than 4-fold increase in cell accumulation after cotransduction with ICN1 and p21 retroviral vectors (Figure 7D). We conclude that $\mathrm{Hrb}$ is critically important for the induction of p21 protein in ICN1-expressing thymocytes, most likely via Hrb's ability to enhance uptake of transferrin.
Hrb is regulated by Notch signaling in buman T-ALL cell lines and is required for leukemia cell proliferation and survival. To determine whether the observed interplay among Notch, Hrb, and iron metabolism may function in human T-ALL as well, we utilized the Notch-dependent T-ALL cell lines DND41, T-ALL1, KOPTK1, and SUPT1. GSI treatment of DND41 and T-ALL1 cells decreased the transcript levels of $\mathrm{Hrb}$ (Figure 8A), as was observed with the mouse T6E cell line (Figure 2A). Knockdown of Hrb resulted in a decreased accumulation of human T-ALL cells as well as decreased survival, as assessed by annexin V/PI staining (Figure 8, B-D). Our data suggest that $\mathrm{Hrb}$ plays a role in the efficient utilization of iron via transferrin. Thus, inefficient use of iron in Hrb-depleted cells should confer greater sensitivity to the iron chelator desferrioxamine (DFO). Indeed, reducing Hrb levels in DND41 cells resulted in greater sensitivity to iron chelation (Figure 8E). Consistent with the increased surface levels of CD71 in $\mathrm{Hrb}^{-/-}$cells, treatment with DFO at $2.0 \mu \mathrm{M}$ in KOPTK1 cells resulted in significantly greater surface CD71 (Figure 8F).

Iron is critical for $T$ cell precursor development and for ICN1-induced leukemogenesis. To determine whether iron itself is required for thymocyte development, we depleted thymocyte-OP9DL1 cocultures of iron by addition of DFO. This caused a dramatic loss of thymocyte numbers (Figure 9A). Interestingly, $\mathrm{Hrb}^{-/-} \mathrm{DN}$ cells were more sensitive to depletion of iron with DFO, consistent with their reduced ability to utilize iron-loaded transferrin.

Together, the results above indicated a critical role for Hrb in mediating in vitro survival of ICN1-transduced T cell precursors and human T-ALL cell lines, by driving efficient utilization of iron. Reduced iron uptake might similarly explain the decreased incidence (Figure $3 \mathrm{~A}$ ) or delay in development (Figure 4B) of T-ALL in mice lacking Hrb. If so, suppression of iron uptake in WT mice might delay their development of T-ALL. We reasoned that placing 

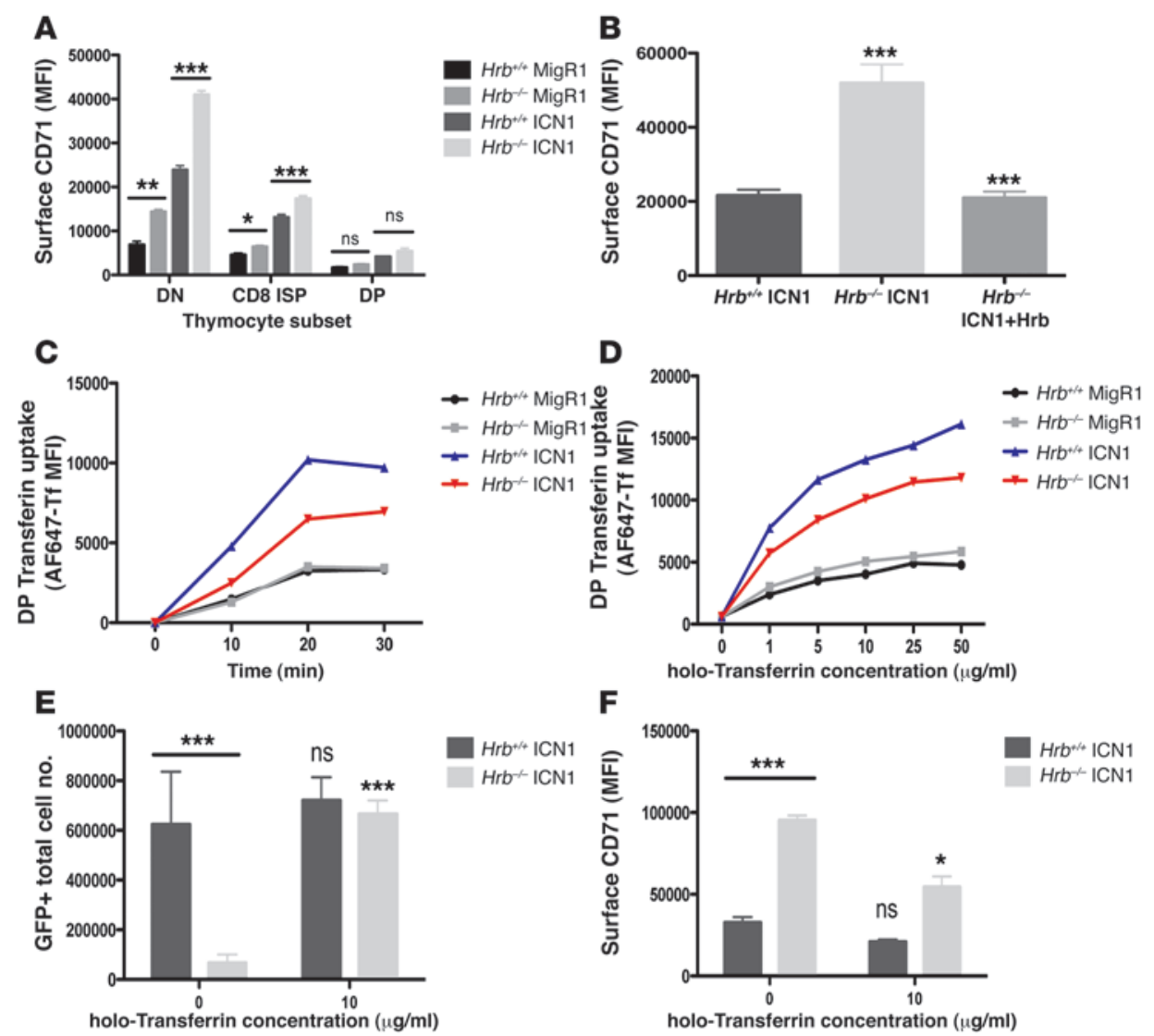

$\mathbf{F}$
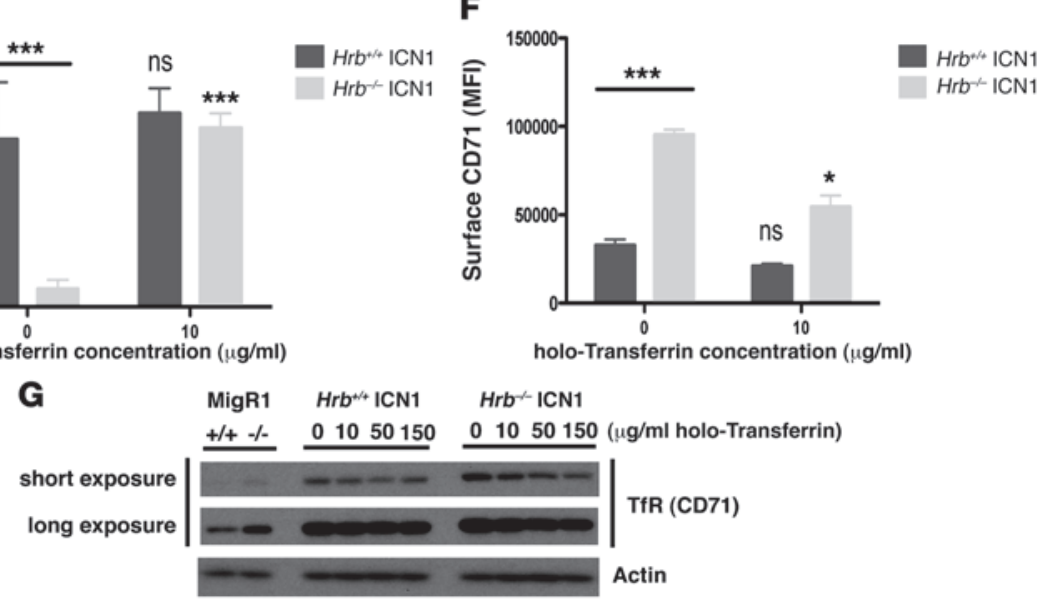

Figure 6

Hrb loss leads to increased surface TfR (CD71) and inefficient transferrin uptake in the context of oncogenic Notch signaling. (A) Surface levels of TfR (CD71) on $\mathrm{Hrb}^{+/+}$and $\mathrm{Hrb}^{-/-}$MigR1- and ICN1-transduced thymocytes cocultured on OP9DL1 stromal beds. (B) Surface levels of CD71 on $\mathrm{Hrb}^{+/+}$and $\mathrm{Hrb}^{-/-}$MigR1- and ICN1-transduced hematopoietic precursor cells cocultured on OP9 stromal beds. (C) Uptake of $10 \mu \mathrm{g} / \mathrm{ml}$ Alexa Fluor 647-conjugated transferrin in $\mathrm{Hrb}^{+/+}$and $\mathrm{Hrb}^{-/-}$MigR1- and ICN1-transduced DP thymocytes. (D) Uptake of Alexa Fluor 647-conjugated transferrin (0-50 $\mathrm{\mu g} / \mathrm{ml})$ in $\mathrm{Hrb}^{+/+}$and $\mathrm{Hrb}^{-/}$MigR1- and ICN1-transduced DP thymocytes. Uptake experiments repeated several times with representative graphs shown here. Each point on the curves represents an independently transduced well in the experiment. (E) $\mathrm{Hrb}^{+/+}$and $\mathrm{Hrb}^{-/-}$ICN1-transduced GFP-positive hematopoietic precursors with and without holo-Tf addition. (F) Surface CD71 levels on GFP-positive

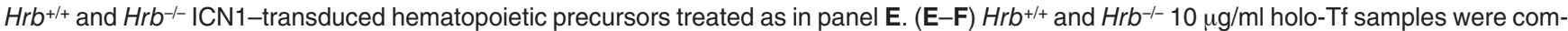
pared with respective $0 \mu \mathrm{g} / \mathrm{ml}$ holo-Tf samples. (G) Western blot of lysates prepared from $\mathrm{Hrb}^{+/+}$and $\mathrm{Hrb}^{-/-}$MigR $1-$ transduced thymocytes and $\mathrm{Hrb}^{+/+}$and $\mathrm{Hrb}^{-/-}$ICN1-transduced thymocytes grown on OP9DL1 cocultures in the presence of increasing concentrations of holo-Tf. Lysates blotted for TfR: short exposure (top); longer exposure (bottom); and actin (loading control). DN, CD4-CD8- DN; CD8 ISP, CD4-CD8+ ISP; DP, CD4 ${ }^{+}$CD8 + DP. Data are shown as mean \pm SD. ${ }^{\star} P<0.05$; ${ }^{* \star} P<0.01$; ${ }^{* \star} P<0.001$.

recipient mice on a low-iron diet would reduce their total body iron stores and decrease availability of the iron to developing leukemic blasts. Cohorts of WT mice transplanted with WT ICN1transduced BM cells were placed on either a low-iron diet or normal mouse chow for up to 48 days. Mice that were transplanted with control (MigR1-transduced) BM cells on the low-iron diet engrafted, survived, and appeared well, although they did develop iron-deficiency anemia (hemoglobin $7.8 \mathrm{~g} / \mathrm{dl}$ and mean corpuscular volume [MCV] 43.9 femtoliters [fL], compared with control mice with hemoglobin of $11.7 \mathrm{~g} / \mathrm{dl}$ and MCV $47.9 \mathrm{fL}$ ). Remark- ably, mice transplanted with ICN1-expressing BM demonstrated significantly delayed death from ICN1-induced leukemogenesis if they were maintained on the iron-restricted diet $(P=0.0001$ by Mantel-Cox log rank analysis) (Figure 9B).

\section{Discussion}

We report an important role for Hrb in T-ALL by using mice with conditional deletion of CBP and mice transplanted with ICN1transduced BM. Our data demonstrate that Hrb upregulation occurs in the vast majority of CBP-null $\mathrm{T}$ cell lymphomas, as a 
A
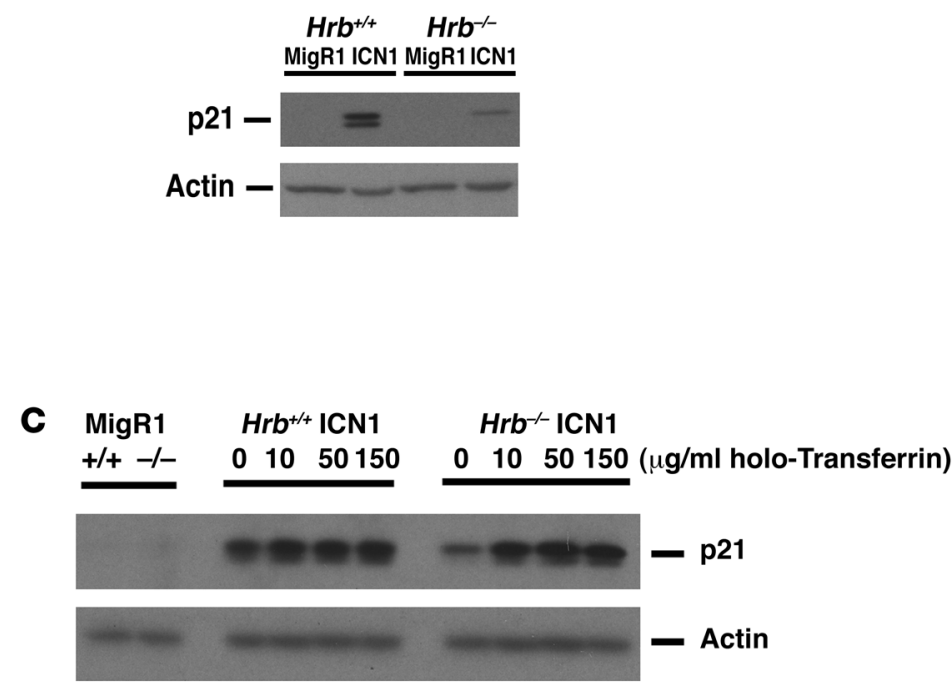
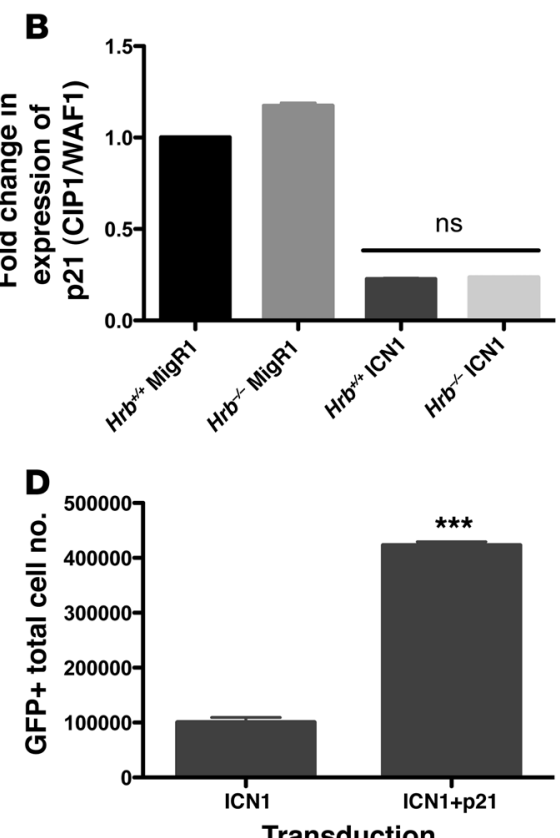

Figure 7

Addition of excess holo-transferrin restores p21 protein levels in ICN1-transduced Hrb ${ }^{-/-}$T cell precursors. (A) Western blot of lysates prepared from $\mathrm{Hrb}^{+/+}$and $\mathrm{Hrb}^{-/-}$MigR1- and ICN1-transduced thymocytes grown on OP9DL1 cocultures and harvested 5 days after transduction. Lysates blotted for p21 and actin (loading control). (B) Quantitative RT-PCR of mRNA isolated from the $\mathrm{Hrb}^{+/+}$and $\mathrm{Hrb}^{-/-}$MigR1- and ICN1-transduced thymocytes grown as in panel A. (C) Western blot of lysates from Figure 6G blotted for p21 and actin (loading control). (D) GFP-positive cell number of ICN1- and ICN1+p21-transduced WT hematopoietic precursors cocultured on OP9 stromal beds for 10 days. Data are shown as mean \pm SD. ${ }^{\star \star \star} P<0.001$.

downstream effect of activated Notch. Several important Notch target genes have been identified since its discovery as a potent oncogene (44). The majority of these target genes play crucial roles in physiologic Notch signaling. Here, we identify Hrb as a direct transcriptional target of Notch. Hrb is not required for physiologic Notch signaling, since thymocyte development is completely normal in $\mathrm{Hrb}^{-/-}$mice. On the other hand, $\mathrm{Hrb}$ is clearly required for efficient Notch-induced lymphomagenesis, as evidenced by a delay in ICN1-induced T-ALL and a reduction in tumor incidence in the CBP-null mouse model. Clues from in vitro proliferation and development clearly suggested a failure to achieve optimal cell survival under the influence of ICN1 expression. Indeed, Hrb was required for survival of Notch-dependent human T-ALL cell lines in culture. Oncogenes (such as myc) that are upregulated by Notch are known to activate the cellular suicide program (45). ICN1 itself simultaneously offsets some of these effects through inhibition of p53 (46). However, lacking Hrb expression, the drive to apoptosis was inadequately suppressed, and we suspect this is a major cellular mechanism by which Hrb supports Notch-mediated lymphomagenesis.

Our data argue that Hrb facilitates oncogenesis by enhancing the ability of cells to take up transferrin. According to this model, in $\mathrm{Hrb}^{-1-}$ cells, particularly under the conditions of enforced proliferation driven by ICN1, iron uptake does not keep pace with the increased metabolic requirements of transformed cells, resulting in a state of iron depletion. This in turn induces the synthesis of CD71 in a failed attempt to acquire more iron from the cell surroundings. If this is unsuccessful, cell survival is compromised, leading to apoptosis (Figure 9C). In such a situation, leukemic progenitor cells cannot survive the stress of transformation in the face of relative iron starva- tion, which could explain the reduced incidence of T-ALL in CBPnull mice. In the case of ICN1-transduced BM, the oncogene is of such high potency that eventually even the severe defect of Hrb loss in transformed cell viability would ultimately be overcome by a rare secondary event that could bypass the apoptotic response. However, in the presence of supra-normal levels of transferrin in culture, $\mathrm{Hrb}$ is no longer required, as cells can compensate for inefficient uptake. It is likely that competition for transferrin within the BM is much more intense than that in vitro, thus amplifying the effect in vivo.

Notch activation has previously been shown to upregulate surface transferrin receptor (TfR) (47), and TfR has recently been shown to be a direct transcriptional target of c-myc (48), itself a direct target of Notch (14). Our work provides the first description at the molecular level of how oncogenic Notch signaling directs the transformed cell to meet increased metabolic demands for needed iron through upregulation of $\mathrm{Hrb}$ to accelerate transferrin uptake. Hrb was previously shown to be essential for efficient transferrin uptake by the use of knockdown experiments (12). Additionally, a role for Hrb in clathrin-mediated relocalization of VAMP7 from the cell surface to the endocytic compartment was demonstrated by Pryor et al. (11). Here, using $\mathrm{Hrb}^{-/-}$mice, we provide an important context to Hrb's role in clathrin-dependent endocytosis of cell surface TfR, downstream of oncogenic Notch signaling. Also, by utilizing a knockdown approach in Notch-dependent T-ALL cell lines, we demonstrate the importance of Hrb in the viability of human leukemia cells.

How does the failure to efficiently take up holo-transferrin lead to the death of ICN1-expressing thymocytes? Although it could result from a general metabolic failure as iron-containing enzymes become depleted, we suspect a more direct cause may be the failure to upregulate the $\mathrm{p} 21$ protein after ICN1 transduction. Much 

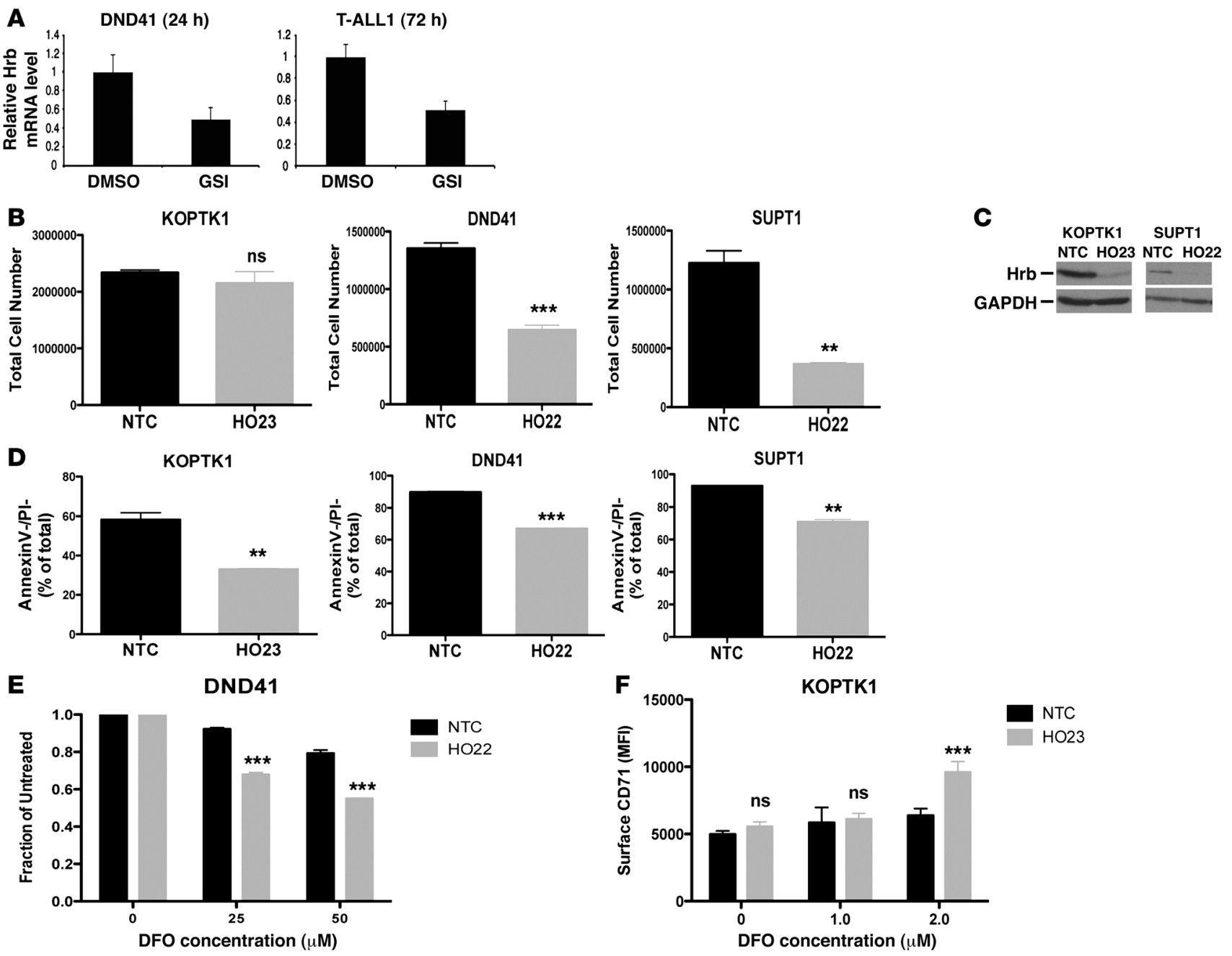

Figure 8

Hrb is regulated by Notch signaling in human T-ALL cell lines and is required for cell proliferation and survival. (A) Quantitative RT-PCR analysis demonstrating the downregulation of Hrb following treatment with GSI $(1 \mu \mathrm{M})$. Human T-ALL cell lines DND41 and T-ALL1 were treated with DMSO or GSI for 24 hours and 72 hours, respectively. Total RNA was prepared for reverse transcription and human Hrb mRNA abundance was measured by quantitative RT-PCR. (B) Nontarget control (NTC) and Hrb knockdown (HO22/HO23) stably transduced T-ALL cell lines were seeded at 100,000 cells/well and cultured for 7 days. Total cell numbers were counted based on forward and side scatter. (C) Western blot of lysates prepared from KOPTK1 and SUPT1 cell lines stably transduced with nontarget control and HO22/HO23 Hrb knockdown lentiviral vectors. Membranes were blotted with Hrb (clone H-300) and GAPDH (loading control). (D) Nontarget control and Hrb knockdown (HO22/HO23) stably-transduced T-ALL cell lines were seeded at 100,000 cells/well and cultured for 7 days. Cell survival was assessed using annexin V/PI staining. (E) DFO sensitivity of DND41 cells stably transduced with nontarget control or HO22. nontarget control or HO22 DND41 T-ALL cells were treated with 0,25 , or $50 \mu \mathrm{M}$ DFO for 4 days. Following treatment, total cell numbers were acquired based on forward/side scatter and normalized to untreated. (F) Surface CD71 levels on NTC and HO23 stably transduced KOPTK1 cells treated with 0, 1.0, and $2.0 \mu \mathrm{M}$ DFO. Data are shown as mean $\pm \mathrm{SD}$. ${ }^{\star \star} P<0.01 ;{ }^{* \star \star} P<0.001$.

focus has been placed on the role of p21 as a tumor-suppressor protein due to its cell cycle inhibitory functions, but there is considerable evidence for a prosurvival function of p21 (49). p21 appears to have a special prooncogenic function in thymocytes because the incidence of $\mathrm{T}$ cell lymphomas is significantly decreased in p21 knockout mice (40). How $\mathrm{p} 21$ is regulated by activated Notch in $\mathrm{T}$ cell precursors is not known, but in cells of the renal glomerulus, it was shown to be due to p53-dependent upregulation of the p21 mRNA (50), and in keratinocytes, p21 is a direct transcriptional target of Notch 1 activation (51). Interestingly, we found the transcript levels of p21 to be equal in ICN1-transduced cells, regardless of their Hrb status. These results suggest a posttranscriptional or posttranslational mechanism of regulation of p21. Fu et al. demonstrated that iron chelation leads to the ubiquitin-independent proteasomal degradation of $\mathrm{p} 21$ protein and a concomitant decrease in nucleocytoplasmic transport of p 21 mRNA (43). It is likely that deficiency in iron utilization in $\mathrm{Hrb}^{-/-}$cells similarly prevented the ICN1-induced upregulation of p21 that occurs at the posttranscriptional level in WT cells, since addition of excess transferrin restored $\mathrm{p} 21$ accumulation. What role $\mathrm{p} 21$ plays in ICN1-induced leukemogenesis is not yet clear, but it is likely that p21 stabilization serves a prosurvival function, as has been shown in other $\mathrm{T}$ cell lymphomas (40). Indeed, coexpression of p21 with ICN1 led to a significant increase in cell accumulation. 
A

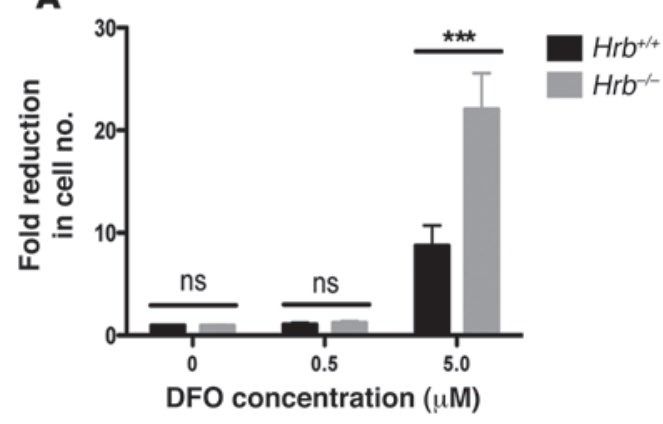

B

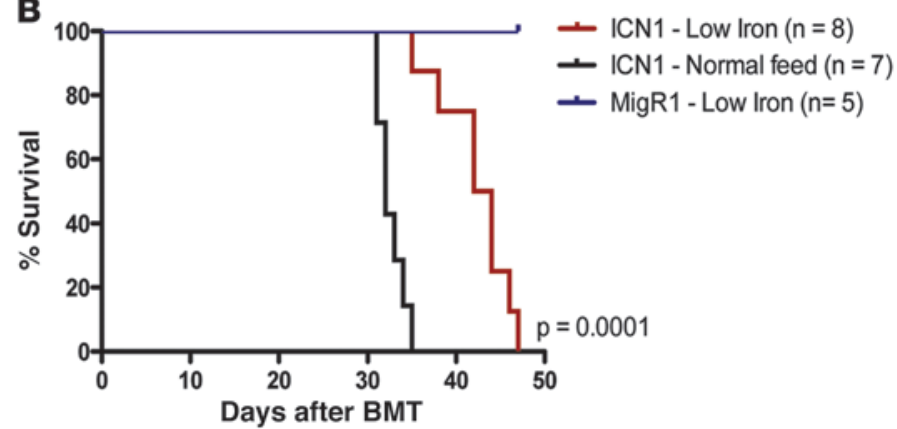

\section{C}

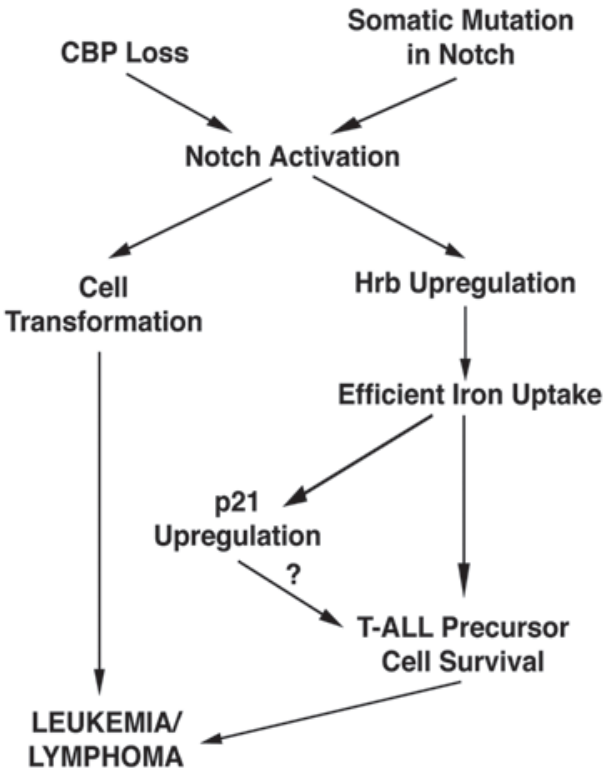

Figure 9

Iron is critical for T cell precursor development and for ICN1-induced leukemogenesis. (A) $\mathrm{Hrb}{ }^{+/+}$and $\mathrm{Hrb}^{-/-} \mathrm{CD} 4-\mathrm{CD} 8^{-} \mathrm{DN}$ cells were seeded on OP9DL1 stromal beds. DFO was added at 0.5 and $5.0 \mu \mathrm{M} 2$ days after cells were plated. Total cell numbers were counted 2 days after treatment. Fold reduction in cell number was calculated in relationship to $0 \mu \mathrm{M}$ DFO. (B) Lethally irradiated recipient mice received 25,000 ICN1transduced BM cells. 7 mice were given normal feed, and 8 mice were given a low-iron diet immediately after transplant and were maintained on their respective diets. Additionally, 5 recipient mice that were transplanted with 25,000 MigR1-transduced BM cells were kept on the same low-iron diet as controls. Maintenance on a low-iron diet delayed death by ICN1-induced leukemogenesis $(P=0.0001$ using log-rank Mantel-Cox test). (C) Model for the role of Hrb in oncogenic Notch signaling: Notch activation after loss of CBP or somatic mutation of Notch1 can lead to Hrb upregulation and cell transformation. Hrb upregulation is required for efficient transferrin uptake, resulting in increased intracellular iron for the transformed cell. This increase in iron uptake leads to increased p21 protein levels. Together, these molecular changes contribute to the survival and proliferation of the Notch-transformed cell, resulting in leukemia. Data are shown as mean $\pm \mathrm{SD}$. ${ }^{\star * \star} P<0.001$.

The concept of nononcogene addiction (NOA) $(52,53)$ is attractive in this case, as we suspect that Notch-transformed cells are "addicted" to their high levels of Hrb. Identification of gene products that in and of themselves are not oncogenic, but that are required for efficient tumor growth, underlies this concept. Hrb overexpression is not known to be tumorigenic but is evidently required for efficient $\mathrm{T}$ cell malignancy. It has been proposed that discovering pathways that allow cancer cells to more efficiently metabolize nutrients may ultimately result in better treatments for cancer. Indeed, depriving cancer cells of iron with the use of an iron chelator $(54,55)$ or limiting the iron intake of mice with cancer (56) has previously been shown to inhibit cancer cell growth. This work provides what we believe is new evidence for the role of iron in the development of Notch-induced leukemias and raises the possibility that $\mathrm{Hrb}$ could be an attractive molecular target for
T-ALL therapy, as it is not required for normal cell development, has a significant role in efficient iron uptake in Notch-transformed cells, and its loss sensitizes cells to iron depletion.

Additionally, our data suggest that the iron status of leukemia patients may be a contributory factor in the disease outcome. Intensified chemotherapeutic protocols for childhood leukemia have necessitated more frequent blood transfusions, which can predispose patients to iron overload (57). It may thus be detrimental to transfuse packed red blood cells into these patients, with little regard for the resulting iron overload that ensues. Although not thought to cause direct tissue damage as does occur in more chronically transfused patients, such as those with thalassemia and sickle cell anemia $(58,59)$, administration of a high iron load concurrently with chemotherapy may serve to enhance the survival properties of residual malignant cells. Future clinical studies should explore 
whether appropriate timing of blood transfusions may improve outcomes in leukemia or other cancer therapeutic trials.

\section{Methods}

Mice. CBP conditional knockout mice and MMTV-Cre mice were previously described (6). $H r b^{+/-}$mice on the background of MMTV-Cre/CBPflox/flox were intercrossed to generate $\mathrm{Hrb}^{+/+}$and $\mathrm{Hrb}^{-/-}$cohorts in the background of CBP deletion. ICN1/CBP-null mice were generated by mating CBPflox/flox mice to mice with ICN1 downstream of a floxed STOP sequence, which have been previously described (13). These mice were, in turn, mated to MMTV-Cre mice to activate ICN1 expression and delete CBP. Recipients for the BMT experiments were 4- to 8-week-old female C57BL/6 mice (Jackson Laboratory). Mice were observed daily for any signs of poor health. Sick mice were sacrificed and screened for tumors. All mouse studies were approved by the Mayo Clinic Animal Care and Use Committee.

Flow cytometry. Antibodies were from BD Biosciences - Pharmingen. Cells were stained for surface expression of the following markers using the antibodies in parentheses: CD4 (RM4-5), CD8 (53-6.7), CD25 (7D4), CD44 (IM7), and CD71 (C2). Cell survival was assessed using annexin V-Cy5 and PI staining (BD Biosciences - Pharmingen). Viable cells were gated according to their forward scatter and side scatter profiles.

Western blotting. Lysates from CBP-null lymphomas were prepared by snap-freezing lymphoma tissue in liquid $\mathrm{N}_{2}$. Snap-frozen lymphoma tissue or PBS-washed T cell precursors and hematopoietic precursors grown on OP9/OP9DL1 stromal beds were lysed in NP-40 lysis buffer (1\% NP-40, $0.5 \%$ sodium deoxycholate, $5 \mathrm{mM}$ EDTA, $50 \mathrm{mM}$ Tris, $\mathrm{pH}$ 7.4, $150 \mathrm{mM}$ $\mathrm{NaCl}$, and a protease inhibitor cocktail from Roche). Blots were probed with antibodies that recognize Notch1 (mN1a; Santa Cruz Biotechnology Inc.), gamma-secretase cleaved Notch1 (VAL1744; Cell Signaling), Hrb (H-300; Santa Cruz Biotechnology Inc.), p21 (M-19, Santa Cruz Biotechnology Inc.), CD71 (Invitrogen), Actin (Millipore), and GAPDH (Trevigen). The affinitypurified Hrb antibody (clone 386-562) was previously described (10).

Real-time RT-PCR. $1 \mu \mathrm{g}$ total RNA isolated from T6E12 cells or KOPTK1 and TALL1 T-ALL cell lines was reverse-transcribed with SuperScript II (Invitrogen) according to the manual. All quantitative RT-PCR reactions were performed in triplicate. Primer sequences for real-time PCRs were as follows: human Hrb forward, 5'-TTCATCAAGTGTGCCTGCTC; human Hrb reverse, 5'-GCATTGGTCTGAAATGGGTT; mouse Hrb forward, 5'-AGCCCTGGCAGAGTTAGACA-3'; mouse Hrb reverse, 5'-CAGGCACTGTTCCAAAGACA-3'; 18S rRNA forward, 5'-GCGCCGCTAGAGGTGAAAT$3^{\prime}$; and $18 \mathrm{~S}$ rRNA reverse, $5^{\prime}$-GGCGGGTCATGGGAATAAC-3'. Hrb and $18 \mathrm{~S}$ rRNA primers were used at a final concentration of $0.4 \mu \mathrm{M}$. Real-time amplification was performed with TaqMan universal PCR Master Mix (Applied Biosystems) and analyzed on the ABI Prism 7900 (Applied Biosystems).

ChIP assay. ChIP was performed using ChIP assay kits (Upstate Biotechnology) as previously described (14). DNA was recovered for quantitative RT-PCR using the SYBR Green system on the ABI 7900HT Sequence Detection System (Applied Biosystems) with the following primers: (a) $\mathrm{Hrb}(-32 \mathrm{~K})$ forward, 5'-TTTGGGTGAACATTCCTGACAA-3'; (b) Hrb (-32 K) reverse, 5'-GGCACTGAGAAATGCGTGTG-3'; (c) Hrb (180 bp) forward, 5'-CTCCGGCAGCCTGTGAGT-3'; (d) Hrb (180 bp) reverse, 5'-CCGGCCAAAGAGCAAGAG-3'; (e) hes1 promoter forward, 5'-CGTGTCTCTTCCTCCCATTG$3^{\prime}$; and (f) hes1 promoter reverse, 5'-CCAGGACCAAGGAGAGAGGT-3'. Each sample was independently prepared at least 2 times and run in duplicate.

OP9/OP9DL1 cocultures. OP9 and OP9DL1 cells were a gift from Kay Medina (Department of Immunology, Mayo Clinic). Magnetic bead-sorted CD4-CD8- DN T cell precursors were isolated from total mouse thymocytes using CD4 and CD8 MACS microbead isolation kits (Miltenyi Biotec). Hematopoietic precursors were isolated from total BM preparations using the Lineage Cell Depletion Kit (Miltenyi Biotec). Precursors were cocultured on irradiated OP9 and OP9DL1. Recombinant murine IL-7 and FLT3L (Peprotech) were added to cultures at a final concentration of $5 \mathrm{ng} / \mathrm{ml}$.

Retroviral vectors and transductions. The MigR1 empty vector, MigRIDNMAML1(residues 13-74), and Mig-ICN1 constructs were previously described (15). Murine Hrb and p21 (CDKN1a) expression vectors carried the respective $\mathrm{cDNA}$ in the XhoI site of MigRI. Production of high-titer ecotropic retroviruses for the T6E12 cell transductions has been described (60). GSI was a gift from Yueming Li (Department of Molecular Pharmacology \& Chemistry, Memorial Sloan-Kettering Cancer Center, New York, New York, USA). PLAT-E cells used to package the retroviral vectors for transductions were a kind gift from Kay Medina (Department of Immunology, Mayo Clinic). OP9/OP9DL1 cocultures of T cell precursors or hematopoietic precursors were spin-infected with retroviral supernatants at room temperature for 2 hours at $1200 \mathrm{~g}$.

Lentiviral production and transduction of the DND41 T-ALL cell line. Lentiviral vectors containing short hairpins to a nontarget control (NTC; SigmaAldrich) and human $\mathrm{Hrb}$ (HO22; Sigma-Aldrich) were produced in 293FT cells (Sigma-Aldrich). T-ALL cell lines (gift from Thomas Look, Department of Pediatric Oncology, Dana-Farber Cancer Institute, Boston, Massachusetts, USA) were spin-infected with viral supernatants at $1200 \mathrm{~g}$ for 1 hour at room temperature.

Transferrin uptake assay and holo-transferrin addition. T cell precursors cocultured on OP9DL1 cells were incubated with $10 \mu \mathrm{g} / \mathrm{ml}$ Alexa Fluor 647conjugated human holo-transferrin (Invitrogen) to prebind transferrin. Labeled transferrin was competed off by incubation with a 50-fold excess of unlabeled human holo-transferrin (Sigma-Aldrich). Samples were stained with additional antibodies and analyzed by flow cytometry for transferrin uptake. For experiments in which excess human holo-transferrin was added, 48 hours after transduction of T cell precursors with MigR1 or ICN1, cells were incubated for an additional 48 hours with 10 to $150 \mu \mathrm{g} / \mathrm{ml}$ holo-transferrin. DFO and FAC (Sigma-Aldrich) were added to cell cultures at the indicated concentrations.

BM transduction and transplantation. Transduction of BM cells harvested from 5-FU-treated mice and subsequent transplantation has been described (18). Complete blood counts were done using a Hemavet 950FS (Drew Scientific Inc.). Low iron mouse feed was from Harlan. Mice showing poor grooming, difficulty getting to feed, and general lethargic behavior were euthanized. Splenocytes and BM were isolated from these mice for analysis.

Statistics. Where appropriate, all statistical analyses were carried out using GraphPad Prism software using a 2-tailed Student's $t$ test or 2-way ANOVA with Bonferroni's post-tests. $P \leq 0.05$ was considered significant. All experiments were performed in triplicate and are presented as mean \pm SD.

\section{Acknowledgments}

We would like to acknowledge financial support from the Joseph Bloom Research Fund, the Fraternal Order of Eagles Cancer Research Fund, the Lymphoma Research Foundation (\#83174), and an NIH-funded training grant (T32 DK07780). We thank Peter Wettstein for help with bone marrow transplantations and Kay Medina for helpful discussion and for the PLAT-E and OP9/OP9DL1 cell lines. We thank Jie Shen (Brigham and Women's Hospital, Boston, Massachusetts, USA) for providing the Notch transgenic mice.

Received for publication September 29, 2009, and accepted in revised form April 19, 2010.

Address correspondence to: Richard J. Bram, College of Medicine, Mayo Clinic, 200 First Street SW, Rochester, Minnesota 55905, USA. Phone: 507.284.2028; Fax: 507.284.3757; E-mail: bramr@mayo.edu. 
1. Aster JC, Pear WS, Blacklow SC. Notch signaling in leukemia. Annu Rev Pathol. 2008;3:587-613.

2. Bray SJ. Notch signalling: a simple pathway becomes complex. Nat Rev Mol Cell Biol. 2006;7(9):678-689.

3. Ellisen LW, et al. TAN-1, the human homolog of the Drosophila notch gene, is broken by chromosomal translocations in T lymphoblastic neoplasms. Cell. 1991;66(4):649-661.

4. Weng AP, et al. Activating mutations of NOTCH1 in human $\mathrm{T}$ cell acute lymphoblastic leukemia. Science. 2004;306(5694):269-271.

5. Izon DJ, et al. Notch1 regulates maturation of CD4+ and CD8+ thymocytes by modulating TCR signal strength. Immunity. 2001;14(3):253-264.

6. Kang-Decker N, et al. Loss of CBP causes T cell lymphomagenesis in synergy with $\mathrm{p} 27 \mathrm{Kip} 1$ insufficiency. Cancer Cell. 2004;5(2):177-189.

7. Fridell RA, Bogerd HP, Cullen BR. Nuclear export of late HIV-1 mRNAs occurs via a cellular protein export pathway. Proc Natl Acad Sci U S A. 1996;93(9):4421-4424

8. Sanchez-Velar N, Udofia EB, Yu Z, Zapp ML. hRIP, a cellular cofactor for Rev function, promotes release of HIV RNAs from the perinuclear region. Genes Dev. 2004;18(1):23-34.

9. Yu Z, Sanchez-Velar N, Catrina IE, Kittler EL, Udofia EB, Zapp ML. The cellular HIV-1 Rev cofactor hRIP is required for viral replication. Proc Natl Acad Sci US A. 2005;102(11):4027-4032.

10. Kang-Decker N, Mantchev GT, Juneja SC, McNiven MA, van Deursen JM. Lack of acrosome formation in Hrb-deficient mice. Science. 2001;294(5546):1531-1533

11. Pryor PR, et al. Molecular basis for the sorting of the SNARE VAMP7 into endocytic clathrin-coated vesicles by the ArfGAP Hrb. Cell. 2008;134(5):817-827.

12. Chaineau M, Danglot L, Proux-Gillardeaux V, Galli T. Role of HRB in clathrin-dependent endocytosis. J Biol Chem. 2008;283(49):34365-34373.

13. Yang X, Klein R, Tian X, Cheng HT, Kopan R, Shen $\mathrm{J}$. Notch activation induces apoptosis in neural progenitor cells through a 53 -dependent pathway. Dev Biol. 2004;269(1):81-94.

14. Weng AP, et al. c-Myc is an important direct target of Notch 1 in T-cell acute lymphoblastic leukemia/ lymphoma. Genes Dev. 2006;20(15):2096-2109.

15 . Weng AP, et al. Growth suppression of pre-T acute lymphoblastic leukemia cells by inhibition of notch signaling. Mol Cell Biol. 2003;23(2):655-664.

16. Schmitt TM, de Pooter RF, Gronski MA, Cho SK, Ohashi PS, Zuniga-Pflucker JC. Induction of T cell development and establishment of $\mathrm{T}$ cell competence from embryonic stem cells differentiated in vitro. Nat Immunol. 2004;5(4):410-417.

17. Wettstein P, Strausbauch M, Therneau T, Borson $\mathrm{N}$. The application of real-time PCR to the analysis of $\mathrm{T}$ cell repertoires. Nucleic Acids Res. 2008;36(21):e140.

18. Pear WS, et al. Exclusive development of T cell neoplasms in mice transplanted with bone marrow expressing activated Notch alleles. J Exp Med 1996;183(5):2283-2291.

19. Richardson DR, Ponka P. The molecular mechanisms of the metabolism and transport of iron in normal and neoplastic cells. Biochim Biophys Acta. 1997; 1331(1):1-40.

20. Ponka P, Lok CN. The transferrin receptor: role in health and disease. Int J Biochem Cell Biol. 1999;31(10):1111-1137.

21. Qian ZM, Li H, Sun H, Ho K. Targeted drug deliv- ery via the transferrin receptor-mediated endocytosis pathway. Pharmacol Rev. 2002;54(4):561-587.

22. Gomme PT, McCann KB, Bertolini J. Transferrin: structure, function and potential therapeutic actions. Drug Discov Today. 2005;10(4):267-273.

23. Bowlus CL. The role of iron in T cell development and autoimmunity. Autoimmun Rev. 2003;2(2):73-78

24. Ned RM, Swat W, Andrews NC. Transferrin receptor 1 is differentially required in lymphocyte development. Blood. 2003;102(10):3711-3718.

25. Macedo MF, de Sousa M, Ned RM, Mascarenhas C, Andrews NC, Correia-Neves M. Transferrin is required for early T-cell differentiation. Immunology. 2004;112(4):543-549.

26. Brekelmans $P$, van Soest $P$, Voerman J, Platenburg PP, Leenen PJ, van Ewijk W. Transferrin receptor expression as a marker of immature cycling thymocytes in the mouse. Cell Immunol. 1994;159(2):331-339.

27. Kollia $P$, et al. Molecular analysis of transferrin receptor mRNA expression in acute myeloid leukaemia. Br J Haematol. 2001;115(1):19-24.

28. Smilevska T, et al. Transferrin receptor-1 and 2 expression in chronic lymphocytic leukemia. Leuk Res. 2006;30(2):183-189.

29. Penit C, Vasseur F. Sequential events in thymocyte differentiation and thymus regeneration revealed by a combination of bromodeoxyuridine DNA labeling and antimitotic drug treatment. JImmunol. 1988;140(10):3315-3323.

30. Richardson DR, Ponka P. Identification of a mechanism of iron uptake by cells which is stimulated by hydroxyl radicals generated via the iron-catalysed Haber-Weiss reaction. Biochim Biophys Acta. 1995;1269(2):105-114.

31. Le NT, Richardson DR. The role of iron in cell cycle progression and the proliferation of neoplastic cells. Biochim Biophys Acta. 2002;1603(1):31-46.

32. Yu Y, Kovacevic Z, Richardson DR. Tuning cell cycle regulation with an iron key. Cell Cycle. 2007;6(16):1982-1994.

33. el-Deiry WS, et al. WAF1, a potential mediator of p53 tumor suppression. Cell. 1993;75(4):817-825.

34. Harper JW, Adami GR, Wei N, Keyomarsi K, Elledge $\mathrm{SJ}$. The p21 Cdk-interacting protein Cip1 is a potent inhibitor of $\mathrm{G} 1$ cyclin-dependent kinases. Cell. 1993;75(4):805-816.

35. Xiong Y, Hannon GJ, Zhang H, Casso D, Kobayashi R, Beach D. p21 is a universal inhibitor of cyclin kinases. Nature. 1993;366(6456):701-704.

36. Waga S, Hannon GJ, Beach D, Stillman B. The p21 inhibitor of cyclin-dependent kinases controls DNA replication by interaction with PCNA. Nature. 1994;369(6481):574-578.

37. Luo Y, Hurwitz J, Massague J. Cell-cycle inhibition by independent CDK and PCNA binding domains in p21Cip1. Nature. 1995;375(6527):159-161.

38. Weiss RH, Marshall D, Howard L, Corbacho AM, Cheung AT, Sawai ET. Suppression of breast cancer growth and angiogenesis by an antisense oligodeoxynucleotide to p21(Waf1/Cip1). Cancer Lett. 2003;189(1):39-48.

39. Fan Y, Borowsky AD, Weiss RH. An antisense oligodeoxynucleotide to $\mathrm{p} 21$ (Waf1/Cip1) causes apoptosis in human breast cancer cells. Mol Cancer Ther. 2003;2(8):773-782

40. De la Cueva E, et al. Tumorigenic activity of p21Waf1/Cip1 in thymic lymphoma. Oncogene. 2006;25(29):4128-4132.

41. Suzuki A, Tsutomi Y, Akahane K, Araki T, Miura M. Resistance to Fas-mediated apoptosis: activa- tion of caspase 3 is regulated by cell cycle regulator p21WAF1 and IAP gene family ILP. Oncogene. 1998;17(8):931-939.

42. Asada M, et al. Apoptosis inhibitory activity of cytoplasmic p21(Cip1/WAF1) in monocytic differentiation. EMBO J. 1999;18(5):1223-1234.

43. Fu D, Richardson DR. Iron chelation and regulation of the cell cycle: 2 mechanisms of posttranscriptional regulation of the universal cyclin-dependent kinase inhibitor p21CIP1/WAF1 by iron depletion. Blood. 2007;110(2):752-761.

44. Grabher C, von Boehmer H, Look AT. Notch 1 activation in the molecular pathogenesis of T-cell acute lymphoblastic leukaemia. Nat Rev Cancer. 2006;6(5):347-359.

45. Prendergast GC. Mechanisms of apoptosis by c-Myc. Oncogene. 1999;18(19):2967-2987.

46. Beverly LJ, Felsher DW, Capobianco AJ. Suppression of p53 by Notch in lymphomagenesis: implications for initiation and regression. Cancer Res. 2005;65(16):7159-7168

47. Kelly AP, et al. Notch-induced T cell development requires phosphoinositide-dependent kinase 1 . EMBO J. 2007;26(14):3441-3450.

48. O'Donnell KA, et al. Activation of transferrin receptor 1 by c-Myc enhances cellular proliferation and tumorigenesis. Mol Cell Biol. 2006;26(6):2373-2386.

49. Abbas T, Dutta A. p21 in cancer: intricate networks and multiple activities. Nat Rev Cancer. 2009;9(6):400-414

50. Niranjan T, et al. The Notch pathway in podocytes plays a role in the development of glomerular disease. Nat Med. 2008;14(3):290-298.

51. Rangarajan A, et al. Notch signaling is a direct determinant of keratinocyte growth arrest and entry into differentiation. EMBO J. 2001;20(13):3427-3436.

52. Solimini NL, Luo J, Elledge SJ. Non-oncogene addiction and the stress phenotype of cancer cells. Cell. 2007;130(6):986-988.

53. Luo J, Solimini NL, Elledge SJ. Principles of cancer therapy: oncogene and non-oncogene addiction. Cell. 2009;136(5):823-837.

54. Eberhard Y, et al. Chelation of intracellular iron with the anti-fungal agent ciclopirox olamine induces cell death in leukemia and myeloma cells. Blood. 2009;114(14):3064-3073.

55. Whitnall M, Howard J, Ponka P, Richardson DR. A class of iron chelators with a wide spectrum of potent antitumor activity that overcomes resistance to chemotherapeutics. Proc Natl Acad Sci US A. 2006;103(40):14901-14906.

56. Hann HW, Stahlhut MW, Blumberg BS. Iron nutrition and tumor growth: decreased tumor growth in iron-deficient mice. Cancer Res. 1988;48(15):4168-4170.

57. Halonen P, Mattila J, Suominen P, Ruuska T, Salo MK, Makipernaa A. Iron overload in children who are treated for acute lymphoblastic leukemia estimated by liver siderosis and serum iron parameters. Pediatrics. 2003;111(1):91-96.

58. Comer GM, et al. Transfusion-related chronic liver disease in sickle cell anemia. Am J Gastroenterol. 1991;86(9):1232-1234.

59. Prati D. Benefits and complications of regular blood transfusion in patients with beta-thalassaemia major. Vox Sang. 2000;79(3):129-137.

60. Pear WS, Nolan GP, Scott ML, Baltimore D. Production of high-titer helper-free retroviruses by transient transfection. Proc Natl Acad Sci U S A. $1993 ; 90(18): 8392-8396$. 